\title{
The top heat mode of closed loop oscillating heat pipe with check valves at the top heat mode (THMCLOHP/CV): a thermodynamic study
}

\author{
Nipon Bhuwakietkumjohn and Thanya Parametthanuwat ${ }^{*}$
}

\begin{abstract}
The article reports a recent study on heat flux of the top heat mode closed looped oscillating heat pipe with check valves (THMCLOHP/CV). An experimental system was evaluated under normal operating conditions. The

THMCLOHP/CV was made of a copper tube with an inside diameter of $2.03 \mathrm{~mm}$. The working fluid was water, ethanol and R123 with a filling ratio of $30 \%, 50 \%$ and $80 \%$ with respect to the total volume of the tube. The angles of inclination were $20^{\circ}, 40^{\circ}, 60^{\circ}, 80^{\circ}$ and $90^{\circ}$ from the horizontal axis. The number of turn was 40 turns and 2 check valves. Three lengths of evaporator investigated were 50,100 and $150 \mathrm{~mm}$. The operating temperatures were $45^{\circ} \mathrm{C}$, $55^{\circ} \mathrm{C}$ and $65^{\circ} \mathrm{C}$. Experimental data showed that the THMCLOHP/CV at evaporator length of $50 \mathrm{~mm}$ gave a better heat flux with filling ratio at 50\% when using R123 as working fluid and the operating temperature of $65^{\circ} \mathrm{C}$ at angles of inclination of $90^{\circ}$. It was further found that an evaporator length of $50 \mathrm{~mm}$ was superior in heat flux over other length in all experimental conditions under this study. Moreover, the presence of operating temperature had clearly contributed to raise the heat flux of THMCLOHP/CV, but the heat flux had decreased when evaporator length increased.
\end{abstract}

Keywords: Top heat mode (THM); Oscillating heat pipe (OHP); Check valve (CV)

\section{Background}

The closed loop oscillating heat pipe had a check valve (CLOHP/CV). The heat transfer of this CLOHP/CV occurred because of the self-sustaining oscillatory flow using a vapour or liquid circulation cycle between the heating and cooling sections: latent heat is transferred. Under normal operating conditions, the liquid and vapour are effectively separated into two parts with the liquid in the cooling regions and the vapour in the heating regions. The liquid forms U-shaped columns in individual turns, and these oscillations form waves. Under such flow conditions, the effective heat transfer area is limited by the amplitude of the waves. When the amplitude of oscillatory flow is sufficient and the heat transfer area is not included in the waves, effective working fluid supply to the heat transfer area cannot be obtained and heat transfer

\footnotetext{
* Correspondence: thanya.p@fitm.kmutnb.ac.th

Heat pipe and Nanofluids Technology Research Laboratory (HNTRL), Faculty of Industrial Technology and Management, King Mongkut's University of Technology North Bangkok Prachin Buri Campus, Prachin Buri 25230, Thailand
}

cannot be maintained. However, the installation of check valves in the closed loop eliminates this operating limit whereby a single-direction flow is imposed and the heat transfer area is not restricted by the amplitude of the oscillatory flow. The advantages of a CLOHP/CV are its properties of transferring heat in any orientation, its faster response and its internal structure. Miyazaki et al. (2000) studied the oscillating heat pipe including a check valve under normal operating conditions; the liquid and vapour are effectively separated into two parts with the liquid in the cooling region and the vapour in the heating region. The liquid forms U-shaped columns in individual turns and these oscillations form waves. When the amplitude of oscillatory flow is insufficient and the heat transfer area is not affected by the waves, an effective working fluid supply to the heat transfer area cannot be obtained and the heat transfer cannot be maintained. This operating limit is peculiar to oscillating heat pipes. Charoensawan and Terdtoon (2008) investigated the thermal performance of a horizontal closed loop oscillating heat pipe (HCLOHP) at normal operating

\section{定 Springer}


conditions. The HCLOHPs tested were made of copper capillary tubes with various inner diameters, evaporator lengths and number of turns. The working fluids used within the HCLOHPs were distilled water and absolute ethanol, which were added into the tubes to various filling ratios. The thermal performance of a HCLOHP improves by increasing the evaporator temperature and decreasing the evaporator/effective length. The best performance of all the HCLOHPs occurred at the maximum number of 26 turns. (Rittidech et al. (2010)) investigated the thermal performance of various horizontal closed loop oscillating heat pipe systems with check valves (HCLOHPs/CVs). The results showed that the heat transfer performance of an HCLOHP/CV system could be improved by decreasing the evaporator length. The highest performance of all tested systems was obtained when the maximum number of system check valves was 2 . The maximum heat flux occurred with a 2-mm inner diameter tube, and R123 was determined to be the most suitable working fluid. Rittidech et al. (2007) studied the heat transfer characteristics of CLOHP/CV. The inclination of the CLOHP/CV used in the experiments was $90^{\circ} \mathrm{C}$ to the horizontal. The experimental results showed that the heat flux increases with an increase of ratio of check valve $\left(R_{\mathrm{cv}}\right)$ and decreases with an increased aspect ratio. However, it normally performs better when oriented vertically. Unfortunately, vertical orientation from a horizontal is not always practical. For example, top heat mode orientation is commonly favoured in cooling electronic devices, humidity control in air conditioning systems, etc. Despite these common applications, limited reliable experimental research findings are available on the operation of a top heat mode closed loop oscillating heat pipe with check valves (THMCLOHP/CV) (see in Figure 1). In response to the lack of detailed data, this study focuses on determining the actual thermal performance of such a system.

There are indications that exploratory research are indeed required to study the filling ratio, working fluid, length of evaporator section, operating of temperature and angle of inclination of these on top heat mode in engineering systems. Furthermore, this article aims to study heat flux behaviour of THMCLOHP/CV.

\section{Methods}

\section{Check valves}

The check valve (Figure 2) is a floating type valve that consists of a stainless steel ball and copper tube, in which a ball stopper and conical valve seat are provided at the ends of the check valve's case: a conical valve seat is provided at the bottom of the case and a ball stopper is provided at the top of the case, respectively. The ball can move freely between the ball stopper and conical valve seat. A conical valve seat contacts the stainless steel ball in order to prevent reversal of the flow of the working fluid. The ball stopper allows the working fluid to travel to the condenser section for transferring heat.

\section{Experimental setup}

An important factor that has to be considered in building a THMCLOHP/CV is the design of the tube diameter. For this research, the maximum inner diameter

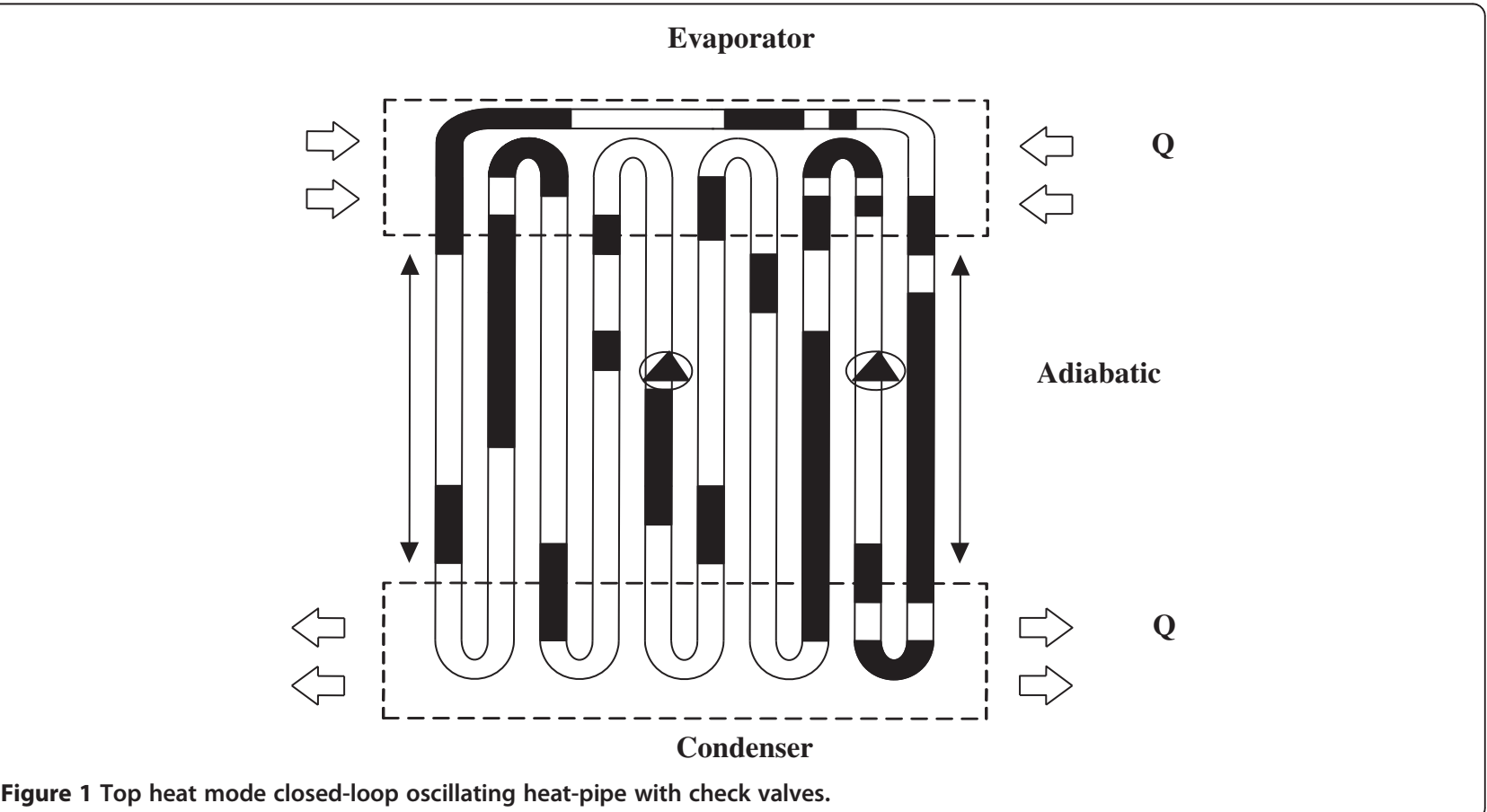




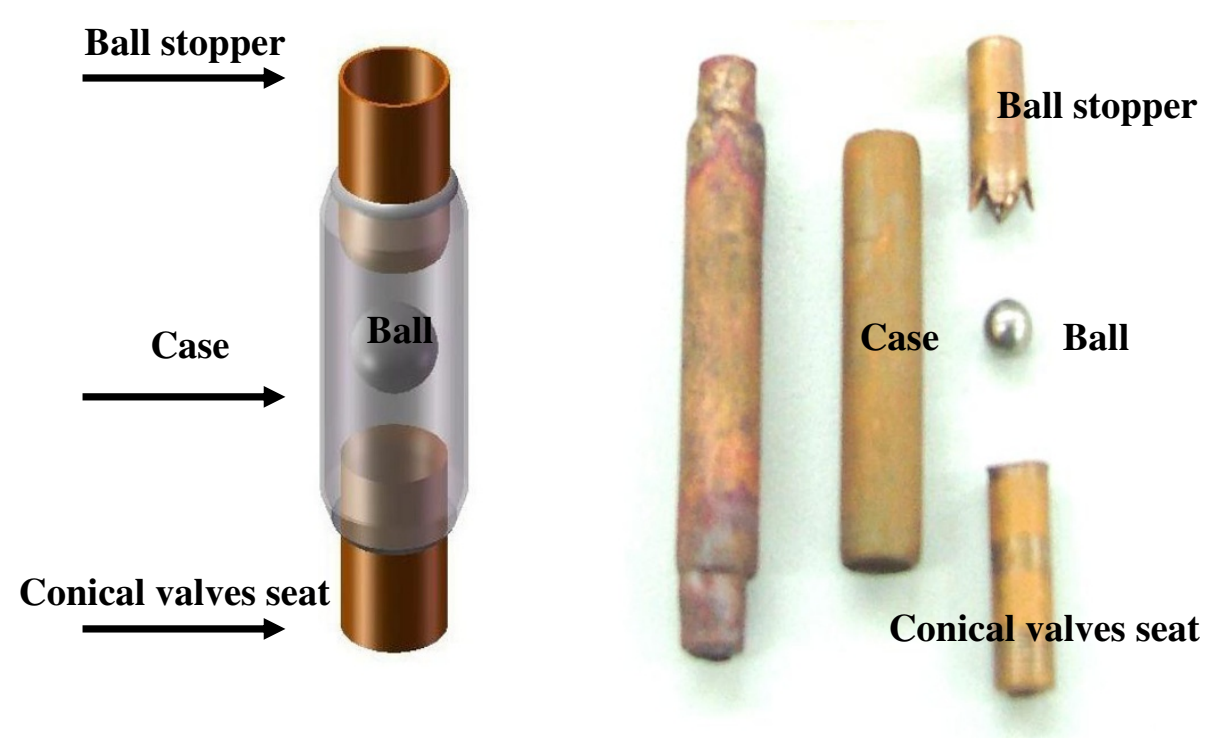

Figure 2 Check valve.

of CLOHP/CV can be defined in Equation 1 (Zorigtkhuu et al. 2006).

$$
d_{i, \max }<2 \sqrt{\frac{\rho}{\rho_{l} g}}
$$

where, $d_{\mathrm{i}, \max }$ is the maximum inner diameter of the capillary tube $(\mathrm{m}), \sigma$ is the surface tension of the fluid $(\mathrm{N} / \mathrm{m}), \rho_{i}$ is the liquid density $\left(\mathrm{kg} / \mathrm{m}^{3}\right)$ and $\mathrm{g}$ is the gravitational acceleration $\left(\mathrm{m} / \mathrm{s}^{2}\right)$. The working principle of the THMCLOHP/CV and the oscillation in the THMCLOHP/CV rely on three driving forces, surface tension, gravity force and oscillating force. These forces are influenced by many parameters. The gravity force is influenced by the inclination angle of the device; the physical features such as diameter size and evaporator section length can have a significant effect on the surface tension, and the heat flux has great effect on the oscillating force.

Figure 3 shows an experimental setup which consists of a THMCLOHP/CV with the lengths of evaporator and adiabatic (which is equal to condenser sections) of 50, 100 and $150 \mathrm{~mm}$. The selected THMCLOHP/CV was made of copper tubes with an internal diameter of $2.03 \mathrm{~mm}$. The evaporator section was heated by a heater and cooled by air and then air inlet flow into the condenser section, while four points of thermocouples (OMEGA type K) were installed at the inlet and outlet of the condenser section to determine the heat transfer rate. The temperature probes were installed at four points on the high temperature copper tube of the evaporator and at one point for ambient to determine the heat loss. A temperature recorder (Yokogawa DX 200 with $\pm 0.1^{\circ} \mathrm{C}$ accuracy, 20 channel input and $-200^{\circ} \mathrm{C}$ to $1,100^{\circ} \mathrm{C}$ measurement temperature range) was used with type $\mathrm{K}$ thermocouples (Omega with $\pm 1^{\circ} \mathrm{C}$ accuracy) to monitor all temperatures at specified times.

During the experiment, the inclination angles were set at $20^{\circ}, 40^{\circ}, 60^{\circ}, 80^{\circ}$ and $90^{\circ}$ from the vertical. The controlled parameters included a tube internal diameter of $2.03 \mathrm{~mm}$, and ethanol and pure water as the working fluid. The variable parameters were the lengths of evaporator 50, 100 and $150 \mathrm{~mm}$ and the working temperatures of $45^{\circ} \mathrm{C}, 55^{\circ} \mathrm{C}$ and $65^{\circ} \mathrm{C}$, respectively. The experiment was conducted as follows: the THMCLOHP/CV was set into the test rig, the temperature of the heater and air inlet was set at the required value and inlet air was supplied to the jackets of the condenser section. After reaching steady state, a continuous temperature was recorded by the data logger. In order to experiment with a wide range of aspect ratios, the following parameters were set corresponding to those shown in Table 1 to formulate the heat transport characteristics of the THMCLOHP/CV.

The working principle of the THMCLOHP/CV and the oscillation in the THMCLOHP/CV relies on three driving forces: surface tension, gravity force and oscillating force. These forces are influenced by many parameters. The gravity force is influenced by the inclination angle of the device. The physical features, such as diameter size and evaporator section length, can have a significant effect on the surface tension. Additionally the heat flux has a great effect on the oscillating force. The temperature change of the condenser section's air inlet and air outlet was measured to calculate the heat flux of THMCLOHP/CV. The 


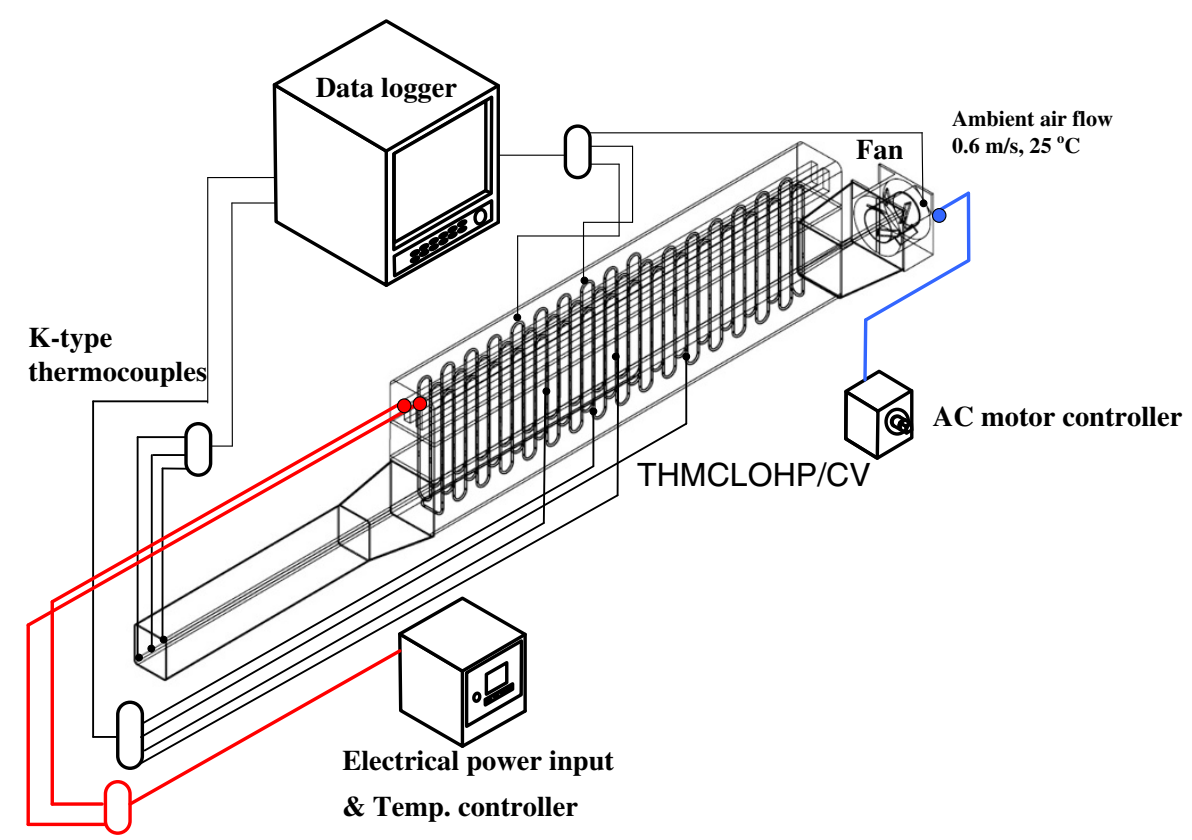

(a)

Ambient air temperature at $25^{\circ} \mathrm{C}$

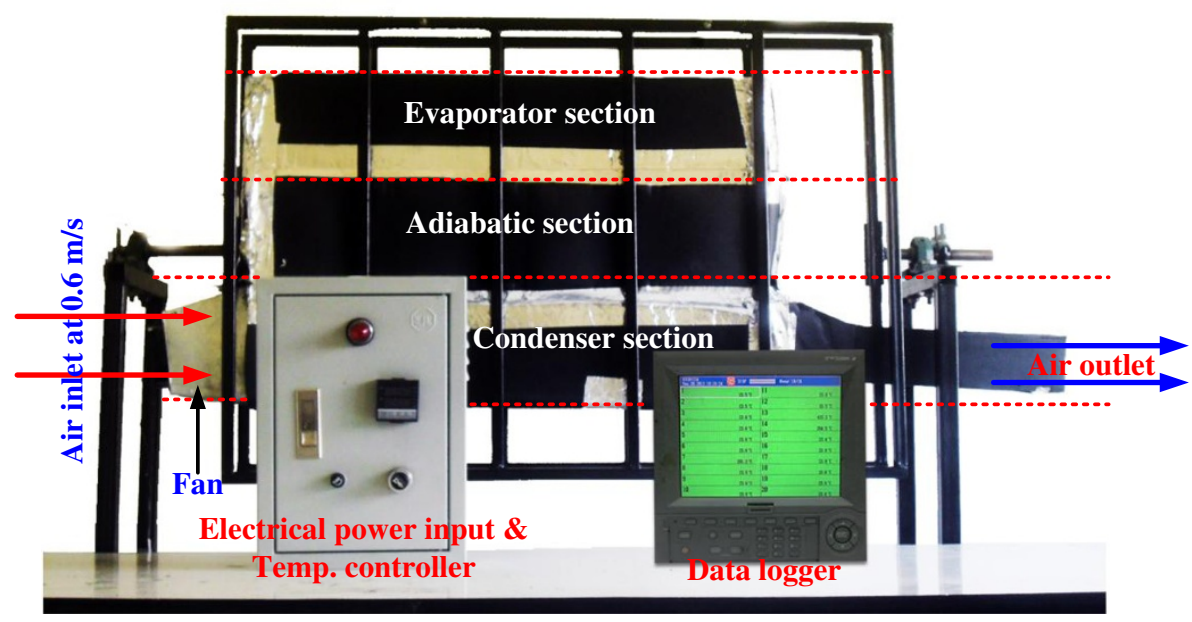

(b)

Figure 3 Experimental setup which consists of a THMCLOHP/CV with the lengths of evaporator and adiabatic. (a) Diagram of the experimental procedure. (b) Experimental setup.

heat transfer rate of THMCLOHP/CV at the condenser section can then be calculated by Equation 2 as follows (Incropera and Dewitt 1996):

$$
Q=\dot{m} C_{p}\left(T_{\text {out }}-T_{\text {in }}\right)
$$

where, $Q$ is the heat transfer rate $(W), \dot{m}$ is the mass flow rate $(\mathrm{kg} / \mathrm{s}), C_{p}$ is the specific heat capacity constant pressure $(\mathrm{J} / \mathrm{kg} \cdot \mathrm{C}), T_{\text {out }}$ is the outlet temperature of the condenser section and $T_{\mathrm{in}}$ is the inlet temperature of the condenser section. In this experiment, the heat flux was calculated using Equation 3 as follows (Rittidech et al. 2010):

$$
q=\frac{Q}{A_{C}}=\frac{Q}{\pi D_{o} L_{C} N}
$$

where $A_{c}$ is the all outer surface area of the tube in the condenser section $\left(\mathrm{m}^{2}\right), Q$ is the heat transfer rate $(W)$, $D_{o}$ is the outside diameter of the capillary tube $(m), L_{c}$ is 
Table 1 Controlled and variable parameters

\begin{tabular}{|c|c|}
\hline $\begin{array}{l}\text { Controlled and variable } \\
\text { parameters }\end{array}$ & Values \\
\hline \multirow{5}{*}{ The variable parameters } & $L_{e} 50,100$ and $150 \mathrm{~mm}$ \\
\hline & $\begin{array}{l}\text { Filling ratio of } 30 \% 50 \% \text { and } 80 \% \\
\text { (by total volume) }\end{array}$ \\
\hline & $\begin{array}{l}\text { Working temperatures of } 45^{\circ} \mathrm{C}, 55^{\circ} \mathrm{C} \\
\text { and } 65^{\circ} \mathrm{C}\end{array}$ \\
\hline & Working fluid of R123, ethanol and water \\
\hline & $\begin{array}{l}\text { Inclinations angles of } 20^{\circ}, 40^{\circ}, 60^{\circ}, 80^{\circ} \\
\text { and } 90^{\circ}\end{array}$ \\
\hline \multirow{4}{*}{$\begin{array}{l}\text { The controlled } \\
\text { parameters }\end{array}$} & Number of check valves, 2 \\
\hline & Air inlet of $0.6 \mathrm{~m} / \mathrm{s}$ \\
\hline & Number of turns 40 turns \\
\hline & Tube inner diameter of $2.03 \mathrm{~mm}$ \\
\hline
\end{tabular}

the condenser length $(m)$ and $N$ is the number of meandering, thus, the calculating standard uncertainty for a type A evaluation. When a set of several repeated readings were taken (for a type A estimate of uncertainty), $\bar{x}$ (arithmetic mean) and SD (standard deviation) can be calculated using Equations 4, 5 and 6 as follows (Beirlant et al. 2004; Hibbeler 2004);

$$
\begin{aligned}
& \bar{X}=\frac{X_{1}+X_{2}+\ldots . X_{n}}{n_{s}} \\
& \mathrm{SD}=\frac{\sqrt{\left(X_{1}-\bar{X}\right)^{2}+\left(X_{2}-\bar{X}\right)^{2}+\ldots+\left(X_{n}-\bar{X}\right)^{2}}}{\left(n_{s}-1\right)} \\
& u_{i, \text { type A }}=\frac{\mathrm{SD}}{\sqrt{n_{s}}}
\end{aligned}
$$

where ' $n$ ' is the number of measurements in the set. The calculating standard uncertainty is a type B evaluation as follows as Equation 7 (Hibbeler 2004; Beirlant et al. 2004).

$$
u_{i, \mathrm{type} \mathrm{B}}=\frac{a}{\sqrt{n_{s}}}
$$

where ' $a$ ' is the semi-range (or half-width) between the upper and lower limits. The combined standard uncertainty was calculated by type A and type B evaluations can be combined, shown by $u_{c}$ in Equation 8 (Hibbeler 2004; Beirlant et al. 2004).

$$
u_{c}=\sqrt{\left(u_{i, \text { type A }}\right)^{2}+\left(u_{i, \text { type B }}\right)^{2}+\ldots+\text { etc. }}
$$

Expand uncertainty, shown by the symbol $\mathrm{U}$.

$$
U=k u_{c}
$$

A particular value of coverage factor gives a particular confidence level for the expanded uncertainty. Most commonly, overall uncertainty was obtained using the coverage factor $k=2$ to give a level of confidence of approximately $95 \%$. Some other coverage factors (for a normal distribution) are as follows (Beirlant et al. 2004; Hibbeler 2004):

$$
\begin{aligned}
& k=1 \text { for a confidence level of approximately } 68 \% \\
& k=2.5 \text { for a confidence level of } 99 \% \\
& k=3 \text { for a confidence level of } 99.7 \%
\end{aligned}
$$

The uncertainty analysis for this study is shown in

\begin{tabular}{|c|c|c|c|c|c|c|c|c|c|}
\hline $\begin{array}{l}\text { Quantity source of } \\
\text { uncertainty }\end{array}$ & $\begin{array}{l}\text { Value of } \\
\text { quantity }\end{array}$ & $\begin{array}{l}\text { Uncertainty } \\
\text { type }\end{array}$ & $\begin{array}{c}\text { Confidence } \\
\text { level }\end{array}$ & $\begin{array}{c}\text { Converge } \\
\text { factor } \\
(k)\end{array}$ & $\begin{array}{c}\text { Standard } \\
\text { uncertainty } \\
\left(u_{i}\right)\end{array}$ & $\begin{array}{c}\text { Sensitivity } \\
\text { coefficient } \\
\left(c_{i}\right)\end{array}$ & $\begin{array}{c}\text { Uncertainty } \\
\text { component } \\
\left(u_{i} c_{i}\right)\end{array}$ & $\begin{array}{c}\text { Combined } \\
\text { uncertainty } \\
\left(u_{c}\right)\end{array}$ & $\begin{array}{c}\text { Expanded } \\
\text { uncertainty } \\
(U)\end{array}$ \\
\hline \multicolumn{10}{|l|}{$\begin{array}{l}\text { Temperature } \\
\text { measurement }\end{array}$} \\
\hline $\begin{array}{l}\text { Thermocouple type } \\
\mathrm{K},{ }^{\circ} \mathrm{C}\end{array}$ & -270 to 1,372 & Type B & $95 \%$ & 2 & 0.57735 & 1 & 0.57735 & & \\
\hline Data logger, ${ }^{\circ} \mathrm{C}$ & -200 to 1,100 & Type B & $95 \%$ & 2 & 0.57735 & 1 & 0.57735 & 0.33362 & 0.66724 \\
\hline $\begin{array}{l}\text { Uncertainty of } \\
\text { mean reading, }{ }^{\circ} \mathrm{C}\end{array}$ & - & Type A & $95 \%$ & 2 & 0.024 & 1 & 0.024 & & \\
\hline \multicolumn{10}{|l|}{ Flow measurement } \\
\hline $\begin{array}{l}\text { Air flow meter, } \mathrm{m} / \mathrm{s} \\
\text { (Operation range, } \\
-30^{\circ} \mathrm{C} \text { to } 140^{\circ} \mathrm{C} \text { ) }\end{array}$ & 0 to 20 & Type B & $95 \%$ & 2 & 0.12 & 1 & 0.12 & - & - \\
\hline
\end{tabular}
Table 2.

\section{Results and discussion}

Effect of inclination angles on heat flux

Figures 4, 5, 6 show the angle of inclination of the THMCLOHP/CV on the heat flux at length of evaporator 50, 100 and $150 \mathrm{~mm}$ for the THMCLOHP/CV with 40 turns, R123, ethanol and pure water as the working fluids

Table 2 Uncertainty analysis result 


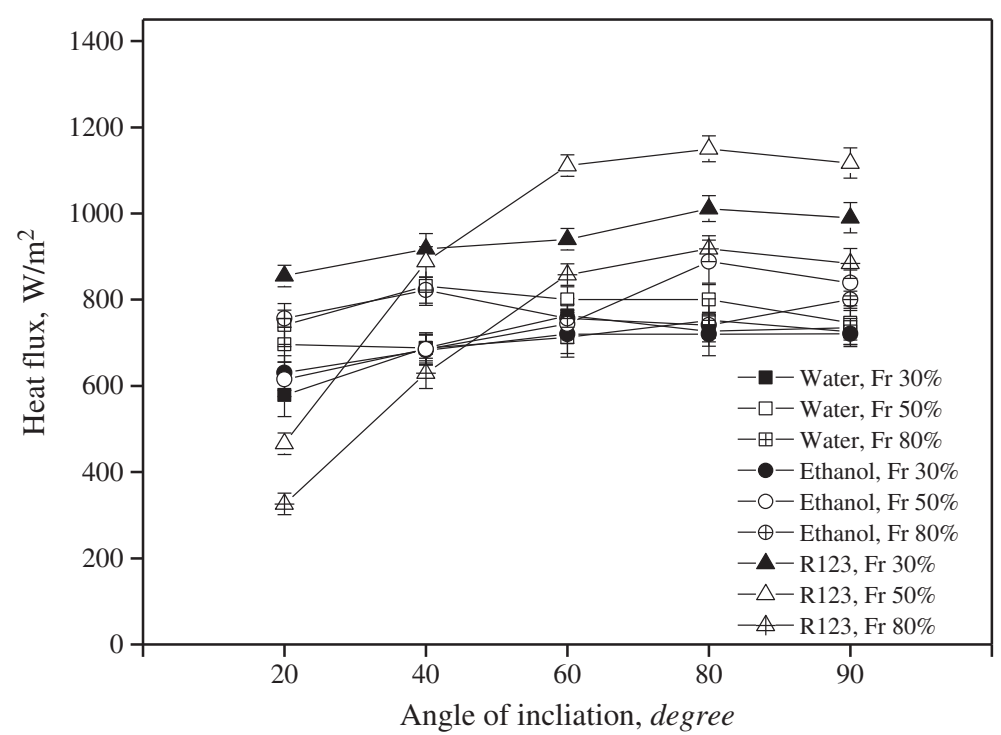

Figure 4 Angle of inclination of THMCLOHP/CV on the heat flux at length of evaporator $50 \mathrm{~mm}$.

and a working temperature of $55^{\circ} \mathrm{C}$ at inclination angles of $20^{\circ}, 40^{\circ}, 60^{\circ}, 80^{\circ}$ and $90^{\circ}$. In Figure 4 , the effect of the angle of inclination of the THMCLOHP/CV on the heat flux at an evaporator length of $50 \mathrm{~mm}$ was remarkable; the heat flux at $80^{\circ}$ using R123 as working fluid was higher than other angles of inclination. Therefore, the best value of heat flux of all was $1,150.53 \mathrm{~W} / \mathrm{m}^{2}$. It can be concluded that the maximum heat flux is obtained when using R123 as the working fluid. It was found that, the heat flux for a filling ratio of $50 \%$ was the highest heat flux. In Figure 5, the results of heat flux were similar to the results at an evaporator length of $100 \mathrm{~mm}$. The heat flux at $80^{\circ}$ using
R123 as working fluid was higher than the other angles of inclination. The best heat flux with an evaporator length of $100 \mathrm{~mm}$ was $697.23 \mathrm{~W} / \mathrm{m}^{2}$. It can be concluded that the maximum heat flux is obtained using R123 as the working fluid. It was found that heat flux for a filling ratio of $50 \%$ was the highest heat flux. In Figure 6, the results of heat flux were similar to the results of those with an evaporator, length of $150 \mathrm{~mm}$. The heat flux at $90^{\circ}$ using R123 as working fluid was higher than other angles of inclination. The best heat flux at an evaporator length of $150 \mathrm{~mm}$ was $309.29 \mathrm{~W} / \mathrm{m}^{2}$. Thus, the maximum heat flux was obtained when using R123 as the working fluid. It was also found

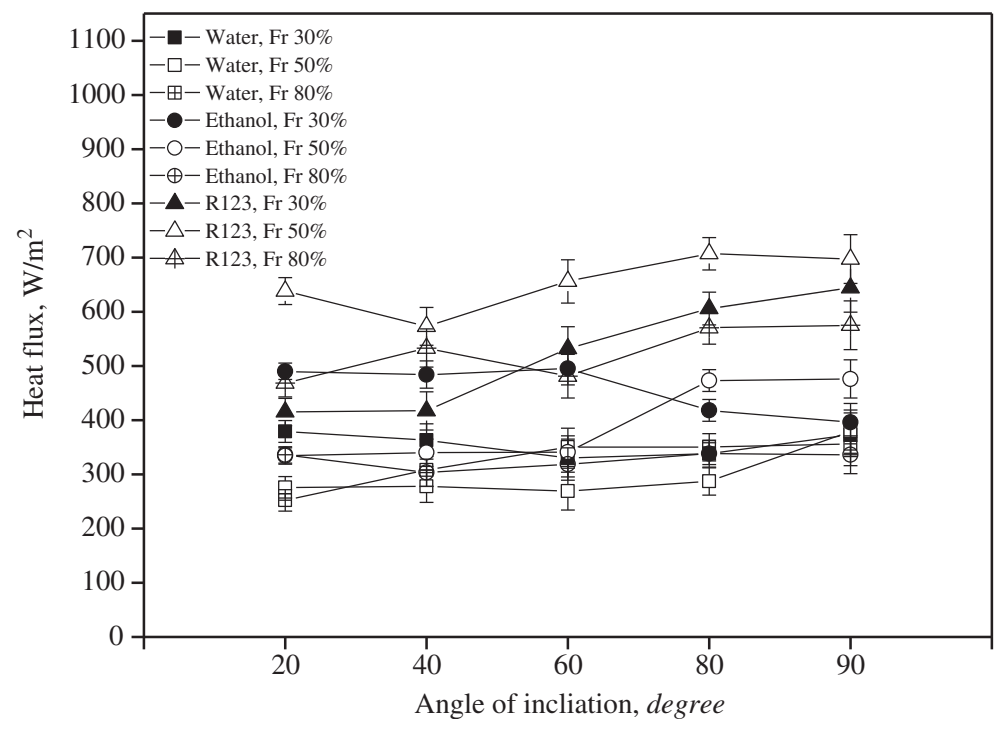

Figure 5 Angle of inclination of THMCLOHP/CV on the heat flux at length of evaporator $100 \mathrm{~mm}$. 


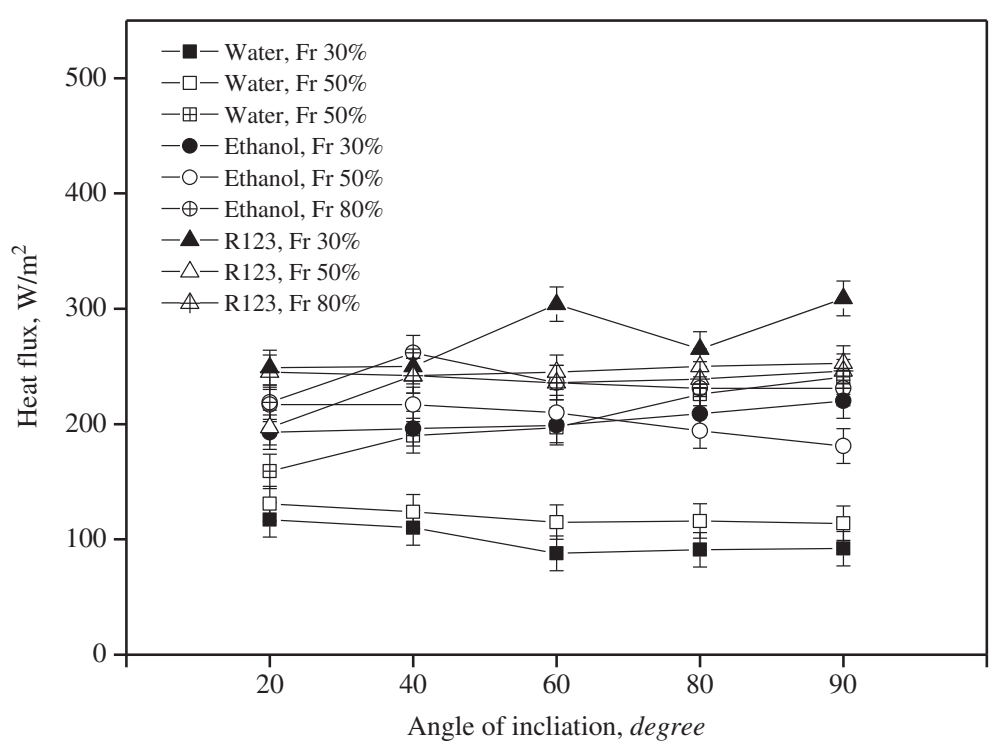

Figure 6 Angle of inclination of THMCLOHP/CV on the heat flux at length of evaporator $150 \mathrm{~mm}$.

that the heat flux for a filling ratio of 30\% was the highest. When the $L_{e}$ increased, then the heat flux clearly decreased (Rittidech et al. 2010; Xu et al. 2005). Moreover, the angle of inclination of THMCLOHP/CV affected the heat flux because of the gravitational head (Dobson 2004; Bhuwakietkumjohn et al. 2012). It depended on fluid density, acceleration from gravity force, tube length and a corner of THMCLOHP/CV to the horizontal line. At the top heating mode, it is hard for the working fluid to flow back to the evaporator section to form steady circulation and resulted in bad heat transfer performance of the THMCLOHP/CV, thereby increasing thermal resistance
(Reay and Kew 2006; Bhuwakietkumjohn and Rittidech 2010). The gravity has a significant influence on the characteristics of heat transfer (Bhuwakietkumjohn and Rittidech 2010; Dobson 2004).

\section{Effect of filling ratio on heat flux}

The filling ratio also had a significant influence on the characteristic of heat transfer. Figure 7 shows the comparative heat flux rates among three filling ratios with $L_{e}$ of 50, 100 and $150 \mathrm{~mm}$. The maximum heat flux occurred at $50 \%$ filling ratio with $L_{e}$ of 50,100 and $150 \mathrm{~mm}$ and was shown as $1,150.53,707.23$ and $309.29 \mathrm{~W} / \mathrm{m}^{2}$, respectively. However,

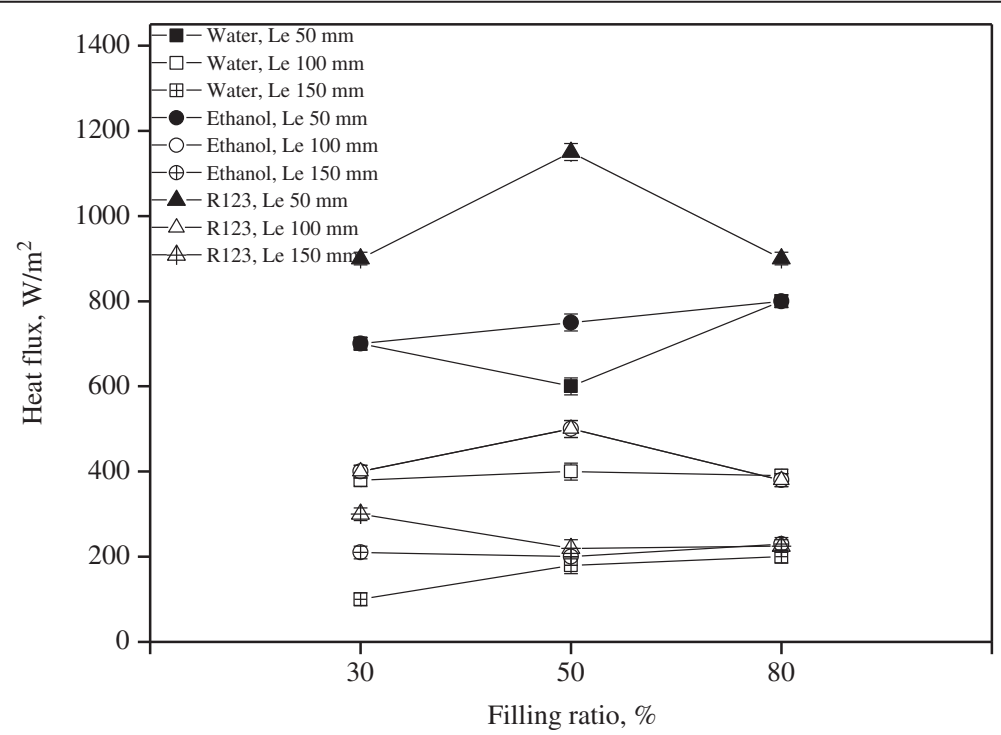

Figure 7 Effect of filling ratio on the heat flux of THMCLOHP/CV at operating temperature of $55^{\circ} \mathrm{C}$. 


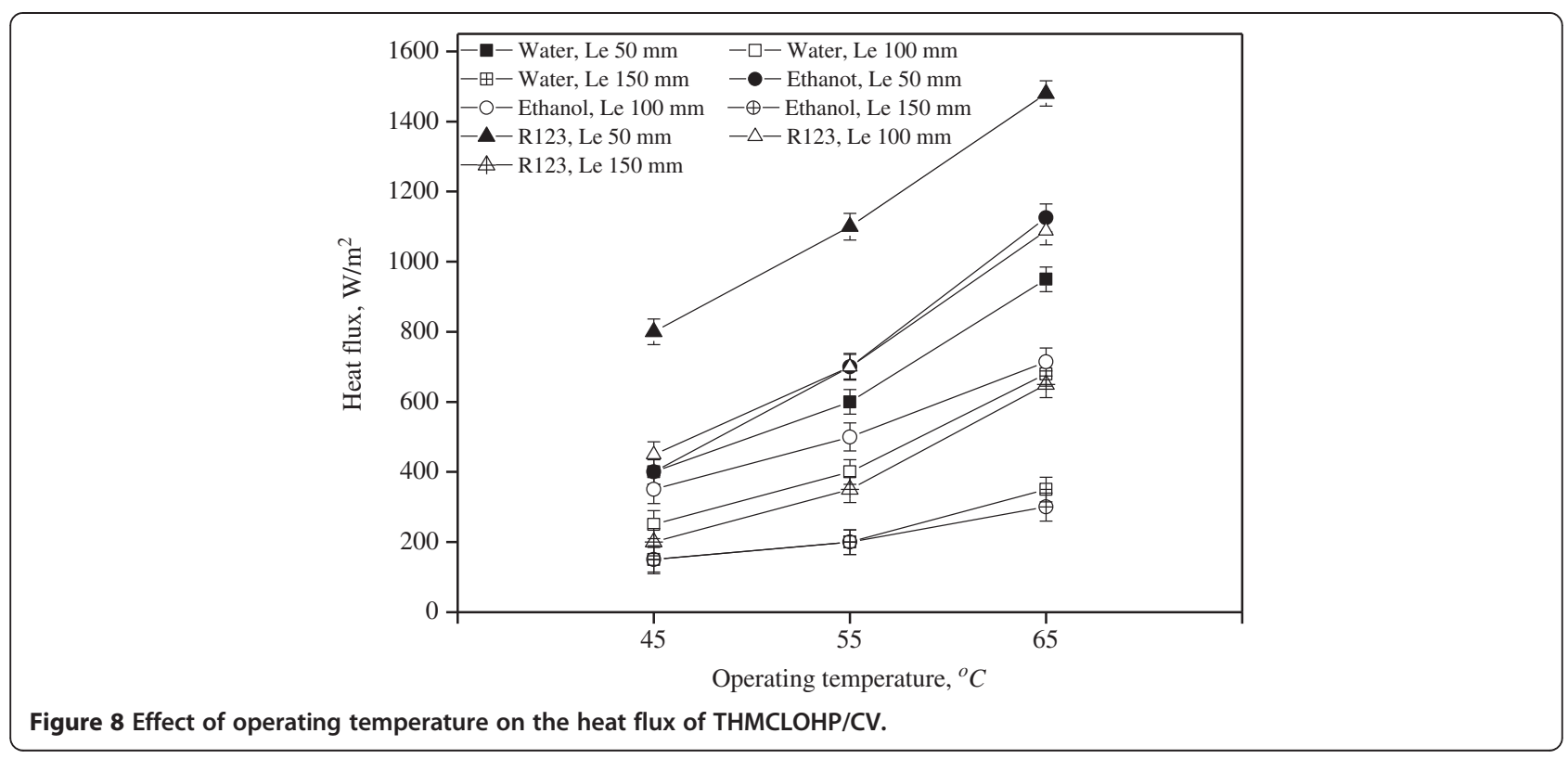

the heat flux of the THMCLOHP/CV was compared between R123, ethanol and water. It can be observed that the heat flux experienced a peak as a function of the filling. The optimum filling ratio for the addition of working fluid in the THMCLOHP/CV was 50\% in which critical slung flow patterns occurred and the highest heat flux was achieved (Bhuwakietkumjohn et al. 2012; Bhuwakietkumjohn and Rittidech 2010; Thongdaeng et al. 2012).

\section{Effect of operating temperature on heat flux}

Dependence of the operating temperature on the heat flux of THMCLOHP/CV filled with the water, ethanol and R123 is shown in Figure 8. Also shown are the data for working fluid. In all cases, the R123 shows superior performance than other working fluid. The maximum heat flux of $1,480 \mathrm{~W} / \mathrm{m}^{2}$ has occurred with the R123 at the operating temperature of $65^{\circ} \mathrm{C}$ with $L_{e}$ of 50 . It can be observed that that the filling ratio has no effect on the ratio of heat flux in the THMCLOHP/CV, but the properties of the working fluid affected the heat flux which depends on the operating temperature (Reay and Kew 2006; Parametthanuwat et al. 2010; Ma et al. 2006).

\section{Effect of working fluid on heat flux}

Their properties are different with respect to their density, surface tension and latent heat of vapourization (Reay and

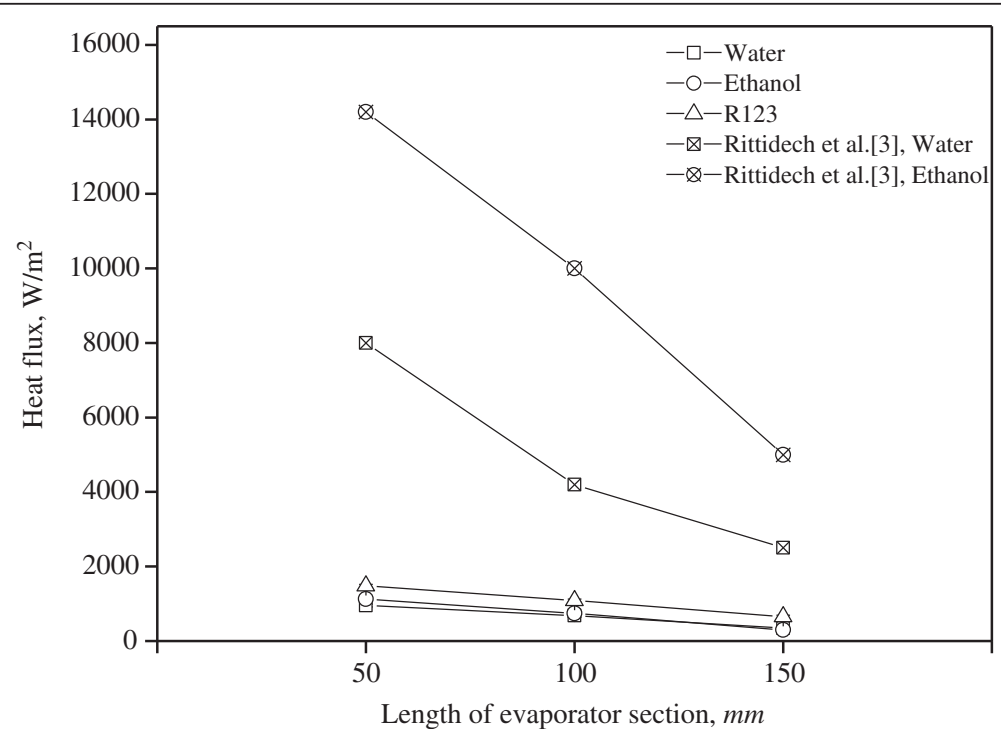

Figure 9 Relationship length of evaporator on heat flux of THMCLOHP/CV. 
Kew 2006; Dobson 2004). Concerning these three properties, the latent heat of vapourization is the major property that has the greatest effect on the motion of the liquid slugs and vapour bubbles in a tube, as well as in the heat transfer rate of the HCLOHP/CVs of Rittidech et al. (2010). Therefore, if the working fluid changes from water and ethanol to R123, the heat flux increases; these are shown in Figures 4, 5, 6. This may be because of R123 that has a low latent heat of vapourization, as well as the fact that the boiling point of R123 is lower than those of the the water and ethanol (Dunn and Reay 1982; Incropera and Dewitt 1996; Bhuwakietkumjohn and Rittidech 2010). The boiling point is an important parameter for the THMCLOHP/CV working temperature and performance. If the boiling point is low, the THMCLOHP/CV will work at low temperatures (Rittidech et al. 2010; Thongdaeng et al. 2012; Koito et al. 2009). However, the latent heat and boiling point of the working fluid also has an effect on THMCLOHP/CV performance.

\section{Effect of evaporator length on heat flux}

In this experiment, the evaporator, adiabatic and condenser were of equal length. This research will concentrate on studying the effect that length of evaporator has on the heat flux of THMCLOHP/CV. The experimental results clearly present the effect length of the evaporator has on heat flux. Figure 9 shows the experimental results, which can be compared to those of Rittidech et al.'s (2010), of horizontal heat mode (HCLOHP/CVs) with ethanol and water; it can be seen that as the $L_{e}$ increases from 50 to $150 \mathrm{~mm}$, the heat flux slightly decreases. In this study, when $L_{e}$ is very long, the boiling phenomenon approaches pool boiling, and at the pool boiling, low heat flux occurs at the evaporator section (Hsu 1962; Nimkon and Rittidech 2011; Cieslinski 2011). On the other hand, at a short $L_{e}$, the boiling phenomenon approaches boiling inside a confined channel at which high heat flux occurs (Reay and Kew 2006; Charoensawan and Terdtoon 2008; Bhuwakietkumjohn et al. 2012). However, this work gave lower heat flux when compared with that of Rittidech et al.'s (2010) who used water to receive heat from the condenser section due to the specific heat capacity being better than the air in this study.

\section{Conclusions}

From the results obtained, it can be concluded that:

- The filling ratio had a slight effect on thermal performance of the THMCLOHP/CV. The thermal performance of the THMCLOHP/CV with $L_{e}$ of $50 \mathrm{~mm}$ was higher than the $L_{e}$ of 100 and $150 \mathrm{~mm}$ at a filling ratio of $50 \%$ when using R123 as working fluid.
- The operating temperature had an effect on the heat flux of the THMCLOHP/CV; when the operating temperature was increased, the heat flux increased.

- The angle of inclination of THMCLOHP/CV affected the heat flux because of the gravitational head. It depended on fluid density, acceleration from gravity force and the length of tube.

- As the $L_{e}$ increases from 50 to $150 \mathrm{~mm}$, the heat flux slightly decreases. The longer $L_{e}$ had occurred, the boiling phenomenon approaches pool boiling, and at pool boiling, a low heat flux occurs.

- It was further found that the physical properties (filling ratio, $L_{e}$, angle of inclination and operating temperature) had effect on the ratio of heat transfer rates in normal operation, but the properties of the working fluid affected the heat transfer rate.

\section{Abbreviations}

$A_{c}$, all outer surface area of tube, $m^{2}$

$Q$, heat transfer rate, $W$

$q$, heat flux $\left(\mathrm{W} / \mathrm{m}^{2}\right)$

$\dot{m}$, mass flow rate, $\mathrm{kg} / \mathrm{s}$

$C_{p}$, specific heat capacity constant pressure, $\mathrm{J} / \mathrm{kg}^{\circ} \mathrm{C}$

$T$, temperature, ${ }^{\circ} \mathrm{C}$

Fr, filling ratio, \%

$L_{e}$, length of evaporator, $\mathrm{mm}$

$d_{i \text {, max }}$, inner diameter of copper tube, $\mathrm{mm}$

$D_{o}$, outside diameter, $\mathrm{m}$

g, gravitational acceleration, $\mathrm{m} / \mathrm{s}^{2}$

$\sigma$, surface tension, $\mathrm{N} / \mathrm{m}$

$\rho$, density of fluid, $\mathrm{kg} / \mathrm{m}^{3}$

in, inlet

out, outlet

\section{Acknowledgements}

Generous support from the Faculty of Industrial and Technology Management through Department of Design and Production Technology of Agricultural Industrial Machinery (Grant No. FITM-5602004-15) to this research is acknowledged. Thanya Parametthanuwat and Nipon Bhuwakietkumjohn were also supported generously by Sampan Rittidech, head of the Heat-Pipe and Thermal Tools Design Research Unit (HTDR), Faculty of Engineering, Mahasarakham University; Thailand, and Thailand Research Fund and Office of The Higher Education Commission.

Received: 13 February 2014 Accepted: 13 May 2014

Published online: 07 August 2014

\section{References}

Beirlant, J, Goegebeur, Y, \& Teugels, J. (2004). Statistics of extremes theory and applications. The Atrium, Southern Gate, Chichester, West Sussex P019 8SQ, England: John Wiley \& Sons Ltd

Bhuwakietkumjohn, N, \& Rittidech, S. (2010). Internal flow patterns on heat transfer characteristics of a closed-loop oscillating heat-pipe with check valves using ethanol and a silver nano-ethanol mixture. Experimental Thermal and Fluid Science, 34(8), 1000-1007. doi:http://dx.doi.org/10.1016/j. expthermflusci.2010.03.003.

Bhuwakietkumjohn, N, Rittidech, S, \& Pattiya, A. (2012). Heat-transfer characteristics of the top heat mode closed-loop oscillating heat pipe with a check valve 
(THMCLOHP/CV. Journal of Applied Mechanics and Technical Physics, 53(2), 224-230. doi:10.1134/s0021894412020101.

Charoensawan, P, \& Terdtoon, P. (2008). Thermal performance of horizontal closed-loop oscillating heat pipes. Applied Thermal Engineering, 28(5-6), 460-466. doi:10.1016/j.applthermaleng.2007.05.007.

Cieslinski, JT. (2011). Flow and pool boiling on porous coated surfaces. Reviews in Chemical Engineering, 27(3-4), 179-190. doi:10.1515/Revce.2011.007.

Dobson, RT. (2004). Theoretical and experimental modelling of an open oscillatory heat pipe including gravity. International Journal of Thermal Sciences, 43(2), 113-119. doi:http://dx.doi.org/10.1016/j. ijthermalsci.2003.05.003.

Dunn, P, \& Reay, D. (1982). Heat pipe. Pergamong Intrnational Library Elsevier; Oxford; United Kingdom.

Hibbeler, RC. (2004). Engineering mechanics statics. Upper Saddle River, New Jersey: Pearson Education.

Hsu, YY. (1962). On the size range of active nucleation cavities on a heating surface. Journal of Heat Transfer, 84, 207-216.

Incropera, FP, \& Dewitt, DP. (1996). Fundamental of heat and mass transfer, 4h Edition. New York: John Wiley \& Son.

Koito, Y, Ikemizu, Y, Torii, S, \& Tomimura, T. (2009). Operational characteristics of a top-heat-type heat transport loop utilizing vapor pressure (fundamental experiments and theoretical analyses). Kagaku Kogaku Ronbunshu, 35(5), 495-501.

$\mathrm{Ma}, \mathrm{HB}$, Hanlon, MA, \& Chen, CL. (2006). An investigation of oscillating motions in a miniature pulsating heat pipe. Microfluidics and Nanofluidics, 2(2), 171-179. doi:10.1007/s10404-005-0061-8.

Miyazaki, Y, Polasek, S, \& Akachi, H. (2000). Oscillating heat pipe with check valves. Paper Presented at the 6th International Heat Pipe Symposium, Chiang Mai, Thailand.

Nimkon, S, \& Rittidech, S. (2011). Effect of working fluids and evaporator temperatures on internal flow patterns and heat transfer rates of a top heat mode closed-loop oscillating heat pipe withcheck valves (thmclohp/Cv). Australian Journal of Basic and Applied Sciences, 5(10), 1013-1019.

Parametthanuwat, T, Rittidech, S, \& Pattiya, A. (2010). A correlation to predict heat-transfer rates of a two-phase closed thermosyphon (TPCT) using silver nanofluid at normal operating conditions. International Journal of Heat and Mass Transfer, 53(21-22), 4960-4965. doi:10.1016/j.jijeatmasstransfer.2010.05.046.

Reay, D, \& Kew, P. (2006). Heat pipe, theory, design and application, Fifth Edition. Butterworth: Heinemann.

Rittidech, S, Pipatpaiboon, N, \& Terdtoon, P. (2007). Heat-transfer characteristics of a closed-loop oscillating heat-pipe with check valves. Apply Energy, 84(5), 565-577. doi:10.1016/j.apenergy.2006.09.010.

Rittidech, S, Pipatpaiboon, N, \& Thongdaeng, S. (2010). Thermal performance of horizontal closed-loop oscillating heat-pipe with check valves Journal of Mechanical Science and Technology, 24(2), 545-550. doi:10.1007/s12206-009-1221-7.

Thongdaeng, S, Rittidech, S, \& Bubphachot, B. (2012). Flow patterns and heat-transfer characteristics of a top heat mode closed-loop oscillating heat pipe with check valves (THMCLOHP/CV). Journal of Engeneering Thermophysics Russia, 21(4), 235-247. doi:10.1134/s1810232812040029.

$\mathrm{Xu}, \mathrm{JL}, \mathrm{Li}, \mathrm{YX}, \&$ Wong, TN. (2005). High speed flow visualization of a closed loop pulsating heat pipe. International Journal of Heat and Mass Transfer, 48(16), 3338-3351. doi:http://dx.doi.org/10.1016/j.jijheatmasstransfer.2005.02.034.

Zorigtkhuu, D, Kim, YS, Kim, H, \& Suh, YK. (2006). Manufacture of an oil-based Fe-Co magnetic fluid by utilization of the pickling liquid of steel. Metals and Materials International, 12(6), 517-523.

doi:10.1186/s40712-014-0005-8

Cite this article as: Bhuwakietkumjohn and Parametthanuwat: The top heat mode of closed loop oscillating heat pipe with check valves at the top heat mode (THMCLOHP/CV): a thermodynamic study. International Journal of Mechanical and Materials Engineering 2014 1:5.

\section{Submit your manuscript to a SpringerOpen ${ }^{\circ}$ journal and benefit from:}

- Convenient online submission

- Rigorous peer review

- Immediate publication on acceptance

- Open access: articles freely available online

- High visibility within the field

- Retaining the copyright to your article

Submit your next manuscript at $\gg$ springeropen.com 